\title{
Sorafenib-induced reversible posterior leukoencephalopathy in patients with renal cell carcinoma: A report of two cases
}

\author{
NOBUKI FURUBAYASHI, TAKAHITO NEGISHI, HIDENORI IWAI, KEI NAGASE and MOTONOBU NAKAMURA
}

Department of Urology, National Hospital Organization Kyushu Cancer Center, Fukuoka 811-1395, Japan

Received February 2, 2017; Accepted May 31, 2017

DOI: $10.3892 /$ mco.2017.1291

\begin{abstract}
Reversible posterior leukoencephalopathy syndrome (RPLS) is a rare clinicoradiological syndrome that is characterized by neurological symptoms, including seizures, headaches, visual abnormalities, confusion and encephalopathy, accompanied by vasogenic edema of the posterior white matter observed on neuroimaging. Sorafenib is an inhibitor of pro-angiogenic receptor tyrosine kinases, such as vascular endothelial growth factor receptor 2, platelet-derived growth factor receptor $\beta$, and vascular endothelial growth factor receptor 3 . In the previous research literature, only one case of sorafenib-induced RPLS, in a patient with hepatocellular carcinoma, has been reported. The current report presents two cases of sorafenib-induced RPLS in patients with metastases from a renal cell carcinoma. In the first case, a 75-year-old female patient developed a fever, fell down and was unable to move her limbs as instructed after 11 days of sorefenib treatment. Brain magnetic resonance imaging (MRI) demonstrated no typical RPLS findings. As all of the symptoms were resolved after sorafenib discontinuation, sorafenib was restarted. However, the patient remained unable to walk steadily and to articulate properly after 10 days. MRI again demonstrated no notable findings, and her condition improved only after discontinuation of the sorafenib. In the second case, a 75-year-old male patient experienced a fall due to loss of consciousness. T2-weighted and fluid-attenuated inversion recovery MRI revealed high-intensity signals on both sides of the cerebellar hemisphere and pons, and also partially on both sides of the frontal lobe. At 33 days after sorafenib discontinuation, he had recovered sufficiently to walk by himself with a walker, and a repeat MRI revealed a significant improvement. Although one case took a longer time, both cases were fortunately reversible by discontinuation of sorafenib treatment and administration of combined-modality therapy (including
\end{abstract}

Correspondence to: Dr Nobuki Furubayashi, Department of Urology, National Hospital Organization Kyushu Cancer Center, Notame 3-1-1, Minami-ku, Fukuoka 811-1395, Japan

E-mail: furubayashi.n@nk-cc.go.jp

Key words: magnetic resonance imaging, renal cell carcinoma, reversible posterior leukoencephalopathy, sorafenib oxygen, steroids, verapamil, digoxin and nicardipine hydrochloride). The oncology community should be alerted to this uncommon and life-threatening adverse event.

\section{Introduction}

Reversible posterior leukoencephalopathy syndrome (RPLS) is a rare clinicoradiological syndrome that is characterized by neurological symptoms, such as seizures, headaches, visual abnormalities, confusion and encephalopathy, accompanied by vasogenic edema of the posterior white matter visible on neuroimaging (1-4). It was initially described in 1996 in patients with elevated blood pressure or eclampsia, and in those receiving immunosuppressive medications (5). The pathogenesis of RPLS is poorly understood, but is thought to be related to disruptions in the blood flow to the posterior circulation secondary to endothelial dysfunction $(3,6,7)$. RPLS has been reported to be associated with various anti-angiogenic therapies (8). In the last few years, an increasing number of cases involving novel targeted drugs, particularly angiogenesis inhibitors, have been reported. Sorafenib (Nexavar ${ }^{\circledR}$; Bayer HealthCare, Montville, NJ, USA; Onyx Pharmaceuticals, Emeryville, CA, USA) is an inhibitor of pro-angiogenic receptor tyrosine kinases, such as vascular endothelial growth factor receptor 2, platelet-derived growth factor receptor $\beta$ and vascular endothelial growth factor receptor $3(9,10)$.

Although sorafenib is associated with various adverse events, cases of sorafenib-induced RPLS have rarely been reported. To the best of our knowledge, only one case of sorafenib-induced RPLS, which occurred in a patient with hepatocellular carcinoma, has been reported in the literature (11). The present report describes the occurrence of RPLS due to the administration of sorafenib in two patients with renal cell carcinoma (RCC). Approval for this report was granted by the ethical review board of National Hospital Organization Kyushu Cancer Center (Fukuoka, Japan), and written informed consent was obtained from the patients.

\section{Case report}

Case 1. A 75-year-old female, who had a previous medical history of well-controlled hypertension and type 2 diabetes, presented to the Department of Urology at National Hospital Organization Kyushu Cancer Center in May 2008, and was diagnosed with a pancreatic tumor metastasized from an RCC, 

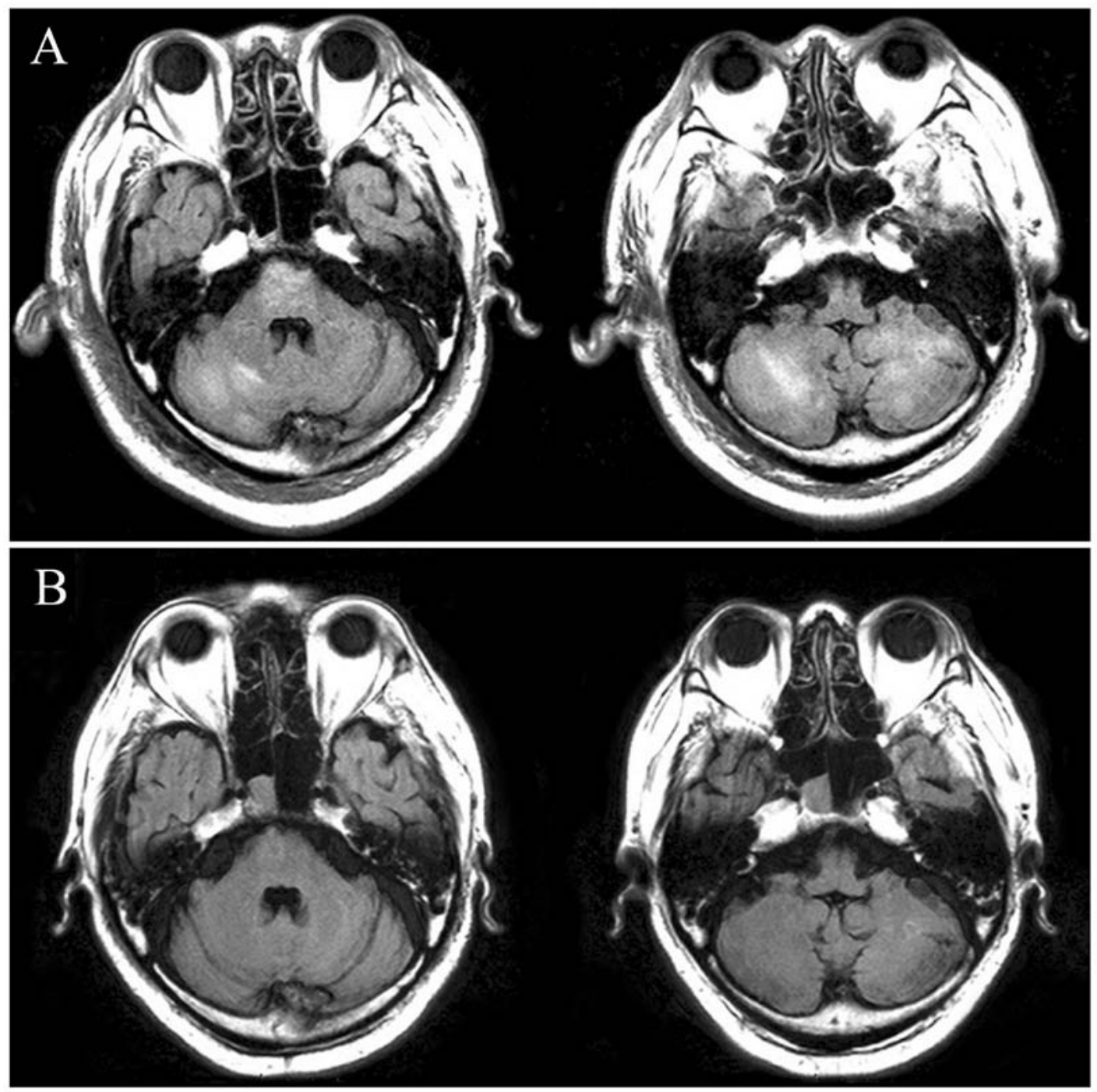

Figure 1. Case 2: Axial fluid-attenuated inversion recovery magnetic resonance images through the cerebellar hemisphere and pons. (A) At presentation of reversible posterior leukoencephalopathy syndrome, high-intensity signals on both sides of the cerebellar hemisphere and pons were observed. (B) 33 days after the discontinuation of sorafenib, the signal intensity had decreased.

which had relapsed 21 years after a radical nephrectomy for a right clear cell RCC. Interferon- $\alpha$ treatment was initially administered for the treatment of the RCC metastasis; however, this therapy was discontinued due to the progression of the disease. Subsequently, sorafenib treatment was commenced at a dose of $400 \mathrm{mg}$ twice daily. After 11 days of sorafenib treatment, the patient developed a fever, fell down, developed urinary incontinence, and was unable to move her limbs as instructed while lying down at home. She was transported to our hospital in an ambulance and sorafenib treatment was stopped. The patient's Glasgow Coma Scale grade was E3V3M5, and her blood pressure was 142/79 $\mathrm{mmHg}$. Brain magnetic resonance imaging (MRI) demonstrated no cerebral hemorrhaging, cerebral infarctions, or metastatic brain tumors, and typical RPLS findings were absent, as before sorafenib administration. All of the symptoms were resolved 8 days after sorafenib discontinuation. Therefore, sorafenib treatment was restarted at $400 \mathrm{mg}$ once daily during hospitalization. However, the patient remained unable to walk steadily and to articulate properly after a further 10 days of sorafenib treatment. Although MRI again demonstrated no typical RPLS findings, the patient was clinically diagnosed with RPLS as the symptoms had recurred with re-administration of sorafenib. The patient's condition was completely resolved through only discontinuation of the sorafenib treatment for 7 days.

Case 2. A 75-year-old male with a previous medical history of well-controlled hypertension and type 2 diabetes presented to the Department of Urology at National Hospital Organization Kyushu Cancer Center in July 2015, and was diagnosed with a metastatic lung and pancreatic tumor from a left RCC. Brain MRI demonstrated no metastatic brain tumors and only an old cerebral infarction in the left cerebellar hemisphere. Left radical nephrectomy was initially performed, and specimens collected at this time led to a pathological diagnosis of clear cell RCC. Thereafter, sorafenib treatment was selected due to renal dysfunction, and was administered at a dose of $400 \mathrm{mg}$ twice daily. The patient was hospitalized for three weeks; however, he only experienced adverse events of grade 2 or less. After 32 days on sorafenib therapy, the patient failed to attend his first hospital visit following discharge. The following day, it was discovered that he had fallen down at home due to a loss 
of consciousness and had extensive bruising on the right side of his body. He was then transported to hospital in an ambulance. The patient's Glasgow Coma Scale grade was E3V2M1 and his blood pressure was $178 / 100 \mathrm{mmHg}$. Sorafenib treatment was therefore discontinued, and immediate treatment with a continuous infusion of nicardipine hydrochloride was administered. Brain computed tomography scans demonstrated the same findings as the brain MRI prior to sorafenib administration; however, at this time, T2-weighted and fluid-attenuated inversion recovery (FLAIR) MRI revealed high-intensity signals predominantly located on both sides of the cerebellar hemisphere and pons, and also partially on both sides of the frontal lobe (Fig. 1A). RPLS was managed with combined-modality therapy and tight blood pressure control, including oxygen, steroids, verapamil, digoxin and nicardipine hydrochloride. At 33 days after sorafenib discontinuation, the patient had recovered sufficiently to walk assisted only by a walker, and repeat MRI revealed a significant improvement on T2-weighted and FLAIR images on both sides of the frontal lobe, cerebellar hemisphere and pons (Fig. 1B). The patients symptoms and imaging findings eventually resolved completely. Another treatment protocol with pazopanib was commenced 5 months after the discontinuation of sorafenib.

\section{Discussion}

The diagnosis of RPLS is primarily dependent on neurological symptoms and neuroradiological imaging findings. However, its diagnosis relies heavily on MRI findings as the symptoms of RPLS can be vague (8). The MRI findings of typical RPLS comprise high-intensity signals on T2-weighted and FLAIR images, predominantly in the posterior regions and in particular the parieto-occipital lobes $(5,6)$.

In the present study, all clinical symptoms observed in Case 1 were consistent with RPLS; the symptoms were relieved following discontinuation, and recurred subsequent to restarting sorafenib. However, no characteristic brain MRI findings were detected in Case 1. Another case of RPLS with no brain MRI findings was reported previously (11). It has also been reported that it is difficult to identify abnormal findings on imaging examinations in the early period of administration of carmofur (12). Fugate and Rabinstein (13) reported that posterior reversible encephalopathy syndrome (PRES) can be also be diagnosed in the presence of normal brain imaging following the elimination of other diagnoses. The symptoms and signs are nonspecific in isolation, thus necessitating brain imaging with the primary intent to exclude alternative diagnoses. However, the diagnosis of PRES is predominantly not radiological; the clinical context and the judgment of the clinician are crucial to making the correct diagnosis. Therefore, when clinical symptoms suggestive of RPLS occur, it is important to start the treatment as early as possible, even if there are no findings on imaging examinations.

Case 2 in the present study demonstrated characteristic neurological symptoms as well as neuroradiological imaging findings; however, the MRI findings included high-intensity signals on FLAIR imaging primarily on both sides of the cerebellar hemisphere and pons, and slightly on both sides of the frontal lobe, but not in the posterior regions. When neuroimaging abnormalities occur elsewhere in the brain, cases are referred to as atypical RPLS. However, involvement outside of the parietal and occipital lobes may not be so rare, as there have been cases of RPLS occurring in the frontal lobes, basal ganglia, thalamus and brainstem (14). In one case series, Lee et al (15) reported that $58 \%$ of RPLS patients had brainstem or cerebellar involvement. Considering all of these previous reports, the two patients in the current study were diagnosed with RPLS induced by sorafenib treatment.

Symptoms and imaging abnormalities are generally reversible, and improvements are often observed within days or weeks of drug discontinuation (15). In the two cases in the present study, the symptoms and/or imaging abnormalities improved by discontinuing sorafenib, but it took a longer time in Case 2 than in Case 1. As the patient in Case 1 was a woman living with her partner, the detection of RPLS occurred early in the pathogenesis. However, in Case 2, the patient was a male who lived alone and, as a result, the detection of RPLS was delayed. As he had extensive bruising from falling on the right side of his body, it was estimated that he had remained in the same position for a prolonged period of time. Additionally, it was not possible to control the patient's blood pressure during this time and, therefore, there was a possibility that his brain was damaged, which may explain the long time required for the patient to recover. The Naranjo Adverse Drug Reaction Probability Scale scores for these neurological symptoms associated with leukoencephalopathy were 9 and 7, respectively, indicating the probable association of these events with sorafenib treatment (16).

As sorafenib is widely used in the treatment of RCC, hepatocellular carcinoma and thyroid carcinoma (17-22), the oncology community should be alerted to this uncommon but life-threatening adverse event.

\section{References}

1. Arrillaga-Romany IC and Dietrich J: Imaging findings in cancer therapy-associated neurotoxicity. Semin Neurol 32: 476-486, 2012.

2. Marinella MA and Markert RJ: Reversible posterior leucoencephalopathy syndrome associated with anticancer drugs. Intern Med J 39: 826-834, 2009.

3. Seet RC and Rabinstein AA: Clinical features and outcomes of posterior reversible encephalopathy syndrome following bevacizumab treatment. QJM 105: 69-75, 2012.

4. Fugate JE, Claassen DO, Cloft HJ, Kallmes DF, Kozak OS and Rabinstein AA: Posterior reversible encephalopathy syndrome: Associated clinical and radiologic findings. Mayo Clin Proc 85: 427-432, 2010

5. Hinchey J, Chaves C, Appignani B, Breen J, Pao L, Wang A, Pessin MS, Lamy C, Mas JL and Caplan LR: A reversible posterior leukoencephalopathy syndrome. N End J Med 334: 494-500, 1996.

6. Lee EQ, Arrillaga-Romany IC and Wen PY: Neurologic complications of cancer drug therapies. Continuum (Minneap Minn) 18: 355-365, 2012.

7. Feske SK: Posterior reversible encephalopathy syndrome: A review. Semin Neurol 31: 202-215, 2011.

8. Kim CA, Price-Hiller J, Chu QS, Tankel K, Hennig R, Sawyer MB and Spratlin JL: Atypical reversible posterior leukoencephalopathy syndrome (RPLS) induced by cediranib in a patient with metastatic rectal cancer. Invest New Drugs 32: 1036-1045, 2014.

9. Wilhelm SM, Carter C, Tang L, Wilkie D, McNabola A, Rong H, Chen C, Zhang X, Vincent P, McHugh M, et al: BAY 43-9006 exhibits broad spectrum oral antitumor activity and targets the RAF/MEK/ERK pathway and receptor tyrosine kinases involved in tumor progression and angiogenesis. Cancer Res 64: 7099-7109, 2004. 
10. Govindarajan R, Adusumilli J, Baxter DL, El-Khoueiry A and Harik SI: Reversible posterior leukoencephalopathy syndrome induced by RAF kinase inhibitor BAY 43-9006. J Clin Oncol 24: e48, 2006.

11. Dogan E, Aksoy S, Arslan C, Dede DS and Altundag K: Probable sorafenib-induced reversible encephalopathy in a patient with hepatocellular carcinoma. Med Oncol 27: 1436-1437, 2010.

12. Kuzuhara S: Leucoencephalopathy induced by carmofur. Annual Review Shinkei: 263-275, 1988.

13. Fugate JE and Rabinstein AA: Posterior reversible encephalopathy syndrome: clinical and radiological manifestations, pathophysiology, and outstanding questions. Lancet Neurol 14: 914-925, 2015.

14. Ahn KJ, You WJ, Jeong SL, Lee JW, Kim BS, Lee JH, Yang DW, Son YM and Hahn ST: Atypical manifestations of reversible posterior leukoencephalopathy syndrome: Findings on diffusion imaging and ADC mapping. Neuroradiology 46: 978-983, 2004.

15. Lee VH, Wijdicks EF, Manno EM and Rabinstein AA: Clinical spectrum of reversible posterior leukoencephalopathy syndrome. Arch Neurol 65: 205-210, 2008.

16. Naranjo CA, Busto U, Sellers EM, Sandor P, Ruiz I, Roberts EA, Janecek E, Domecq C and Greenblatt DJ: A method for estimating the probability of adverse drug reactions. Clin Pharmacol Ther 30: 239-245, 1981

17. Escudier B, Eisen T, Stadler WM, Szczylik C, Oudard S, Siebels M, Negrier S, Chevreau C, Solska E, Desai AA, et al TARGET Study Group: Sorafenib in advanced clear-cell renal-cell carcinoma. N Engl J Med 356: 125-134, 2007.
18. Stadler WM, Figlin RA, McDermott DF, Dutcher JP, Knox JJ, Miller WH Jr, Hainsworth JD, Henderson CA, George JR, Hajdenberg J, et al; ARCCS Study Investigators: Safety and efficacy results of the advanced renal cell carcinoma sorafenib expanded access program in North America. Cancer 116: 1272-1280, 2010.

19. Beck J, Procopio G, Bajetta E, Keilholz U, Negrier S, Szczylik C, Bokemeyer C, Bracarda S, Richel DJ, Staehler M, et al: Final results of the European Advanced Renal Cell Carcinoma Sorafenib (EU-ARCCS) expanded-access study: a large open-label study in diverse community settings. Ann Oncol 22: 1812-1823, 2011.

20. Llovet JM, Ricci S, Mazzaferro V, Hilgard P, Gane E, Blanc JF, de Oliveira AC, Santoro A, Raoul JL, Forner A, et al; SHARP Investigators Study Group: Sorafenib in advanced hepatocellular carcinoma. N Engl J Med 359: 378-390, 2008.

21. Cheng AL, Kang YK, Chen Z, Tsao CJ, Qin S, Kim JS, Luo R, Feng J, Ye S, Yang TS, et al: Efficacy and safety of sorafenib in patients in the Asia-Pacific region with advanced hepatocellular carcinoma: a phase III randomised, double-blind, placebo-controlled trial. Lancet Oncol 10: 25-34, 2009.

22. Brose MS, Nutting CM, Jarzab B, Elisei R, Siena S, Bastholt L, de la Fouchardiere C, Pacini F, Paschke R, Shong YK, et al; DECISION investigators: Sorafenib in radioactive iodine-refractory, locally advanced or metastatic differentiated thyroid cancer: a randomised, double-blind, phase 3 trial. Lancet 384: 319-328, 2014. 